\title{
DIURNAL PERIODICITY IN THE ACTIVITY OF THE GOMMON SOLE, SOLEA VULGARIS QUENSEL
}

by

\author{
H. KRUUK
}

(State Institute for Fisheries Research, IJmuiden, Netherlands, and Laboratory for Comparative Physiology, University of Utrecht, Netherlands) *

\section{CONTENTS}

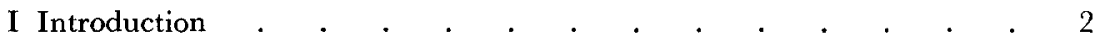

II Evidence for daily fluctuations in the activity of the Sole . . . $\quad$. 2

1 Periodicity in food intake in the natural habitat and in captivity . 3 Material and methods . . . . . . . . . . 3 Results . . . . . . . . . . . . . . . . . 5

2 Periodicity in the locomotion of captive Soles . $\quad$. $\quad$. $\quad . \quad$. $\quad$. 9 Material and methods . . . . . . . . . . . . 99 Results . . . . . . . . . . . . . . . . . . . 11

3 Conclusions . . . . . . . . . . . . . . . . . 12

III Behaviour patterns important in the daily activity cycle of the Sole $\quad 13$

1 General description . . . . . . . . . . . 13

2 Termination of the activity period: the "digging-in" . . . . 13 Description . . . . . . . . . . . . . 13 Causal factors; experiments on the influence of changes in light intensity 14

3 Beginning of the activity period: the "Omega-jump" . . . . 18 Description . . . . . . . . . . . . . 18

Causal factors; experiments on the influence of changes in light intensity 19

4 Conclusions . . . . . . . . . . . . . . . 20

IV Activity under artificial light conditions . . . . . . . 21

1 Activity in continuous darkness $\quad . \quad$. $\quad . \quad$. . . . . . . . . 21

2 Activity in continuous light . . . . . . . . . . . $\quad$. 23

3 Activity under a 12-hour light cycle . . . . . . . . . $\quad$. 23

4 Conclusions . . . . . . . . . . . . . . . . 24

$\mathrm{V}$ Discussion; relevance to the question of periodicity in trawl catches . $\quad 25$

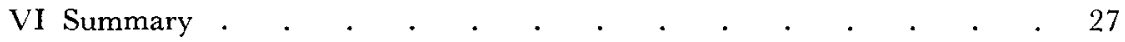

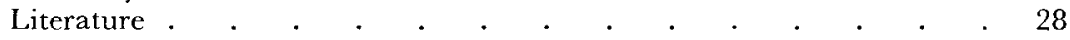

* Present address: Department of Zoology, Oxford, England. 


\section{INTRODUCTION}

During the past fifteen years many data have been gathered at the State Institute for Fisheries Research in the Netherlands on the daily fluctuations which occur in the trawl catches of many species of marine fish. The especially great differences found between the day-time and night-time catches of the Common Sole (Solea vulgaris Quensel) prompted the present investigation of the possible mechanisms behind this phenomenon.

Fluctuations in catches of fish per hour may theoretically be brought about in three ways:

$a$. by changes in the fishing behaviour of the fishermen,

$b$. by changes in the environment of net and fish (e.g., light intensity changes) which alter the likelihood of the fish being caught, or c. by changes in the behaviour of the fish.

Since the netting studies at the Institute are always done in a consistent manner, possibility a. may be discarded. Possibility b. may be operating, but to test this would require observations on the reactions of the fish to nets under several environmental conditions. Such observations were, unfortunately, impossible to carry out. Other evidence suggests, however, that in the case of the Sole this factor is probably of minor importance. It seems likely, then, that possibility c., differences in the behaviour of the fish, must explain most of the differences in the catch of Soles per hour throughout the day. Preliminary observations in a tank suggested that, indeed, large differences do occur between the day-time and night-time behaviour of the Sole.

This paper will attempt to describe the behaviour patterns which play a role in the daily rhythm, the causal factors and effects of those patterns, and the influence of experimental changes in the environment (changes in the light-dark rhythm) on activity; some of these observations will be related to the daily fluctuations in the catch by trawl.

\section{EVIDENCE FOR DAILY FLUGTUATIONS IN THE}

\section{ACTIVITY OF THE SOLE}

Although many studies on daily rhythms in animals and plants have been carried out (reviews in BüNNING 1958, HARkER 1958) relatively little work has been done on fishes, possibly due to the difficulty of recording activity in an aquatic medium. Some aspects of periodicity in fish have been studied by SPENCER (1939) in Cyprinids (locomotion) 
Hoar (1942) in Salmonids (tood intake), Harder and Hempel (1952) in Pleuronectids (locomotion), Kawamoto (1955) in Girella and other species (responses to coloured light), and Hoar (1958) again in Salmonids (locomotion).

Especially concerning the daily fluctuations in locomotion it has become clear from these studies that experimental circumstances may influence the results to a great extent. For instance, in work done with the Plaice (Pleuronectes platessa), Harder and Hempel (loc. cit.) found, by recording the time spent by the fish on the bottom of the tank, a distinct activity peak only during the night. Observations in a large aquarium in Utrecht confirm this. CReUTzBeRG (1942) however, had discovered the Plaice to be almost exclusively dependent on vision for finding its food, and Jones (1952) found on the basis of a study of the position of food in the gut during the course of the day, that in the sea the Plaice indeed feeds during the morning and the evening. It seems unlikely that the observed differences in captive and free-living fishes were based on real differences in the daily rhythms of food intake and locomotory activity; but rather that the natural daily activity rhythm may easily be altered when the animal is brought into a tank in the laboratory. Thus great care must be taken in generalising from observations on the activity of fishes in captivity.

For this reason, investigations on daily activity were made in both aquarium and natural environment, although it was not possible to record the activity in those two habitats in the same way. In the aquarium the distance covered by the animals as indicated by the number of times a recording apparatus was touched, was measured over the 24-hour period; in the natural environment, the time of food intake was determined by studying the position of the food in the intestinal tract at different times of the day. On the basis of observations on the feeding behaviour of the Sole which will be published separately the assumption was made that there is a positive correlation between the time of food intake and time of locomotory activity, and that both factors were, in fact, measures of the locomotory activity.

\section{PERIODICITY IN FOOD INTAKE IN THE NATURAL HABITAT AND IN CAPTIVITY}

\section{Material and methods}

Data on the feeding of Soles in the natural habitat were gathered during a voyage from 22nd to 27th August 1960, when I was a guest on the $210 \mathrm{hp}$. motor cutter IJmuiden 30 "Adeodatus", which fished with a bottom trawl continuously day and night on the Brown Bank Grounds 
in the North Sca at about $53^{\circ}$ L.N. Each haul lasted for about thre' hours and was made at a depth of 16-22 fathoms.

From the Soles caught during this voyage the entire gut was preserved in $4 \%$ formalin immediately upon capture. All the guts from each haul were collected in a glass jar, on which was noted the date, time of beginning and end of the particular haul, and time of prew servation of the guts. In the laboratory 679 guts from 11 such hauls were examined under a binocular microscope for their contents. The intestinal tract was considered to consist of five areas, based on external morphology (fig. 1). First of all, it was noted whether, and if so where,

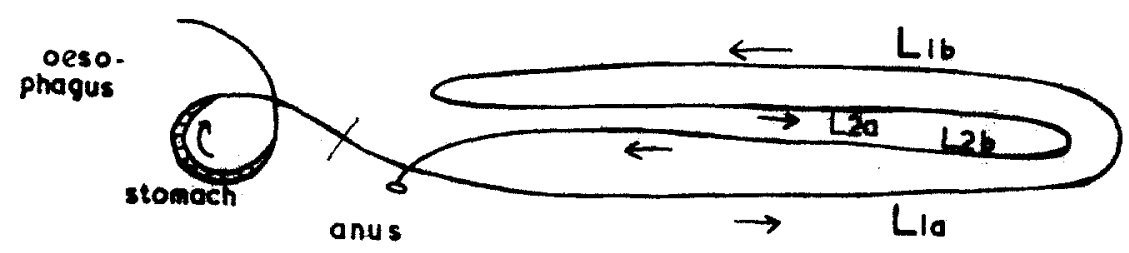

Fig. 1. Scheme of the intestinal tract of the Sole. $L_{1 a}$ and $L_{1 b}=$ First Loop, $L_{2 a}$ and $\mathrm{L}_{2 b}=$ Second Loop.

food was found in the tract. Subjective estimates attempted to determine the amount of food present proved impracticable, the only significant distinction being between the categories "containing food" and "containing nothing". The remains of organisms found were then identified as far as possible. These data will be published in a separate paper. Although notes were also made on the stage of digestion of different food items, these did not prove to be of much value for determining the time of food intake: most prey species either occurred too infrequently or were digested much too rapidly. An exception was the Sand Eel, Ammodytes marinus, but even this provided little information because of the apparent great variability in the speed with which it was digested.

Thus, samples taken at different times of the day were analysed for: a. the percentage of Soles having food in the intestinal tract, and b. the position of the food in the tract.

For statistical analyses the $\chi^{2}$-test was used, with tables from SIEGEL (1956). 


\section{Results}

Percentage of Soles with food in the intestinal tract

Table I shows for the different times of the day the percentage of intestinal tracts which contained food. The high average percentage of guts containing food is consistent with the findings for other flatflshes for this time of the year (e.g., ToDD 1915 for Plaice); in winter this percentage is said to be much lower. The differences between the samples are only slight, and, although the lowest percentage is found at the end of the afternoon, there is no statistically significant trend in the figures.

TAB LE I

Percentages of filled intestines at different times of the day

\begin{tabular}{crrrr} 
Sample no. & Time of sampling & Size of sample & Percentage filled \\
\hline 9 & $22.30-1.30$ & 50 & 84 \\
6 & $1.00-4.00$ & 36 & 78 \\
3 & $4.00-7.00$ & 42 & 72 \\
$12+17$ & $7.00-10.00$ & 64 & 78 \\
13 & $10.30-14.00$ & 49 & 80 \\
$11+14+20$ & $13.30-17.00$ & 154 & 56 \\
7 & $16.00-19.00$ & 34 & 74 \\
$8+15$ & $19.30-22.00$ & 100 & Average 77
\end{tabular}

Place of the food in the intestinal tract

Figures 2 and 3 show for each part of the gut what percentage contained food. In fig. 2, data on the contents of the stomach are not included, first of all because the Sole often brings up food when caught, and this is more likely to influence the results for the stomach than for any other part of the intestine. Also, when the intestinal tract is removed from the animal, the stomach wall is sometimes damaged, so that some of the stomach contents may get lost. Finally, the formalin seems to make the muscular stomach wall contract more than the rest of the intestinal wall, again causing loss of contents. Since these variables will probably work in the same way in all the samples we can compare the stomach contents from the different samples with each other, but not with the other parts of the gut. Figure 3 shows that the "percentage containing food" follows the same course during the day for stomachs as for the first following part of the intestine $\left(\mathrm{L}_{1 \mathrm{a}}\right)$; there is no statistically significant difference between the two distributions. However, com- 


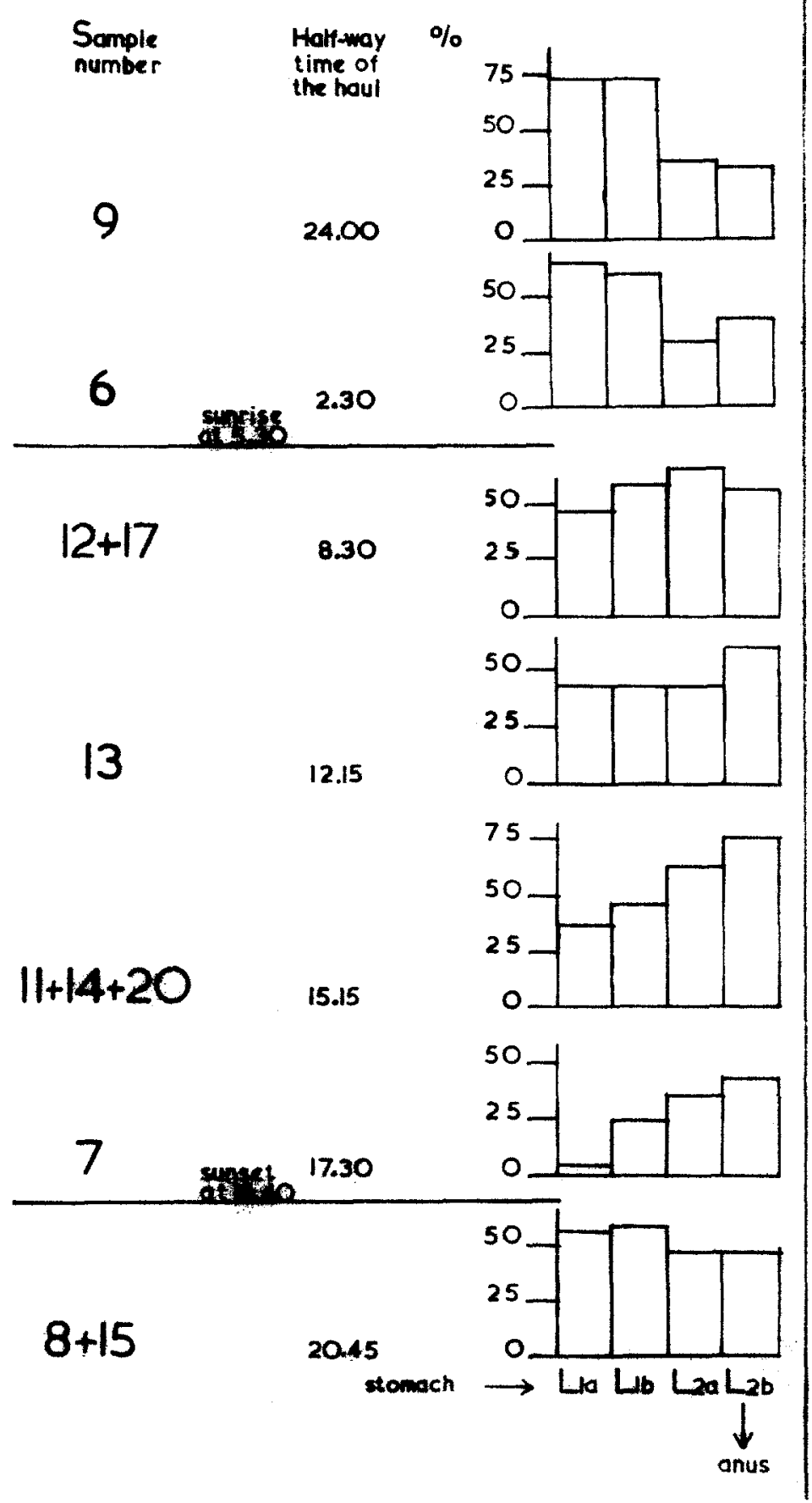

Fig. 2. Distribution within each sample of the percentages of the different parts of the intestine containing food. 

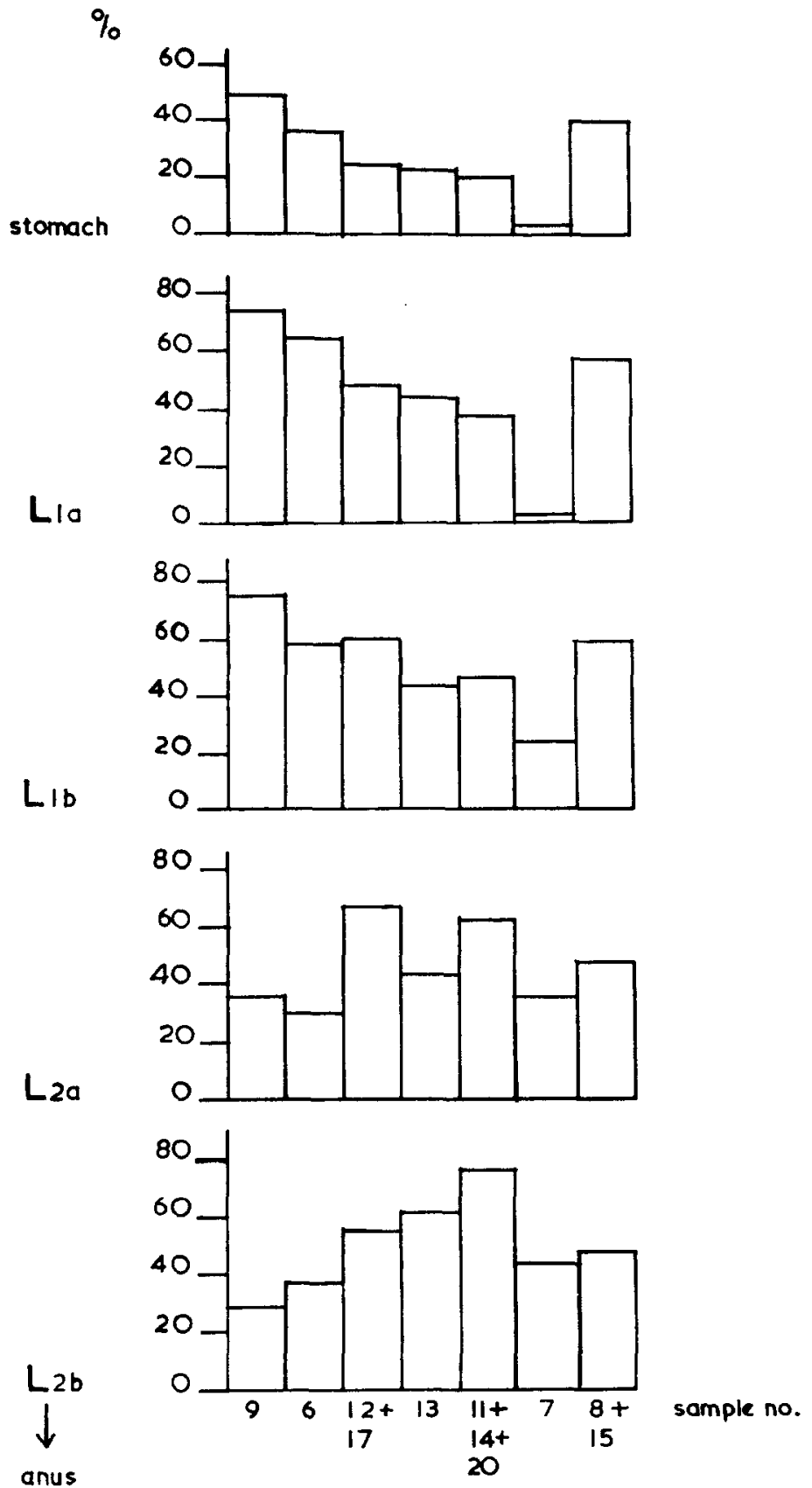

$2400 \quad 8.30 \quad 15.15 \quad 20.45$ half-way time

Fig. 3. The course during the day of the percentage containing food for the different parts of the intestine. 


\section{Number of LI with Food}

Number of L2 with Food

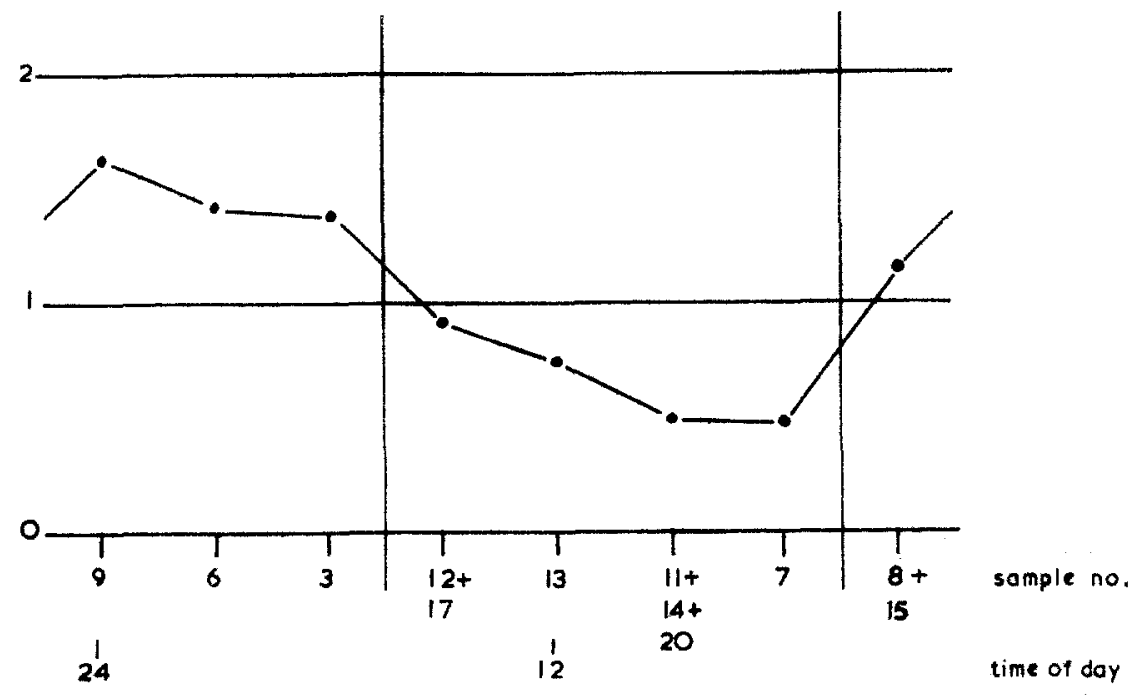

Fig.4. Ratio of the number of First Loops of the intestine containing food versus the number of Second Loops containing food. Sunrise and sunset are indicated by vertical lines. For times of the day corresponding with sample numbers see table $I$.

paring the stomach with the last part of the intestine $\left(L_{2 b}\right)$ a highly significant difference is found in the food distributions $(P<0.001)$.

Thus it appears that during the course of the day there is a gradual shift of food from the beginning to the end of the gut. The stomach and first part of the intestine show a maximum around midnight, while the end part of the intestine shows a maximum at the end of the afternoon. The ratio of filled first loop $\left(\mathrm{L}_{1}\right)$ to filled second loop $\left(\mathrm{L}_{2}\right)$ reverses at sunrise and sunset (fig.4).

Speed of food transport in the intestinal tract of captive fish

An attempt was made to check experimentally the implication of these results that in the Sole the food passes in 18-24 hours through the gut. Since a large variation in speed of transport could be expected, dependent among other things on the quality of the food, large numbers of experimental animals would be necessary to determine this speed with any accuracy; the following observations therefore can be considered as no more than a pilot study. The experiments were made in 
September 1960. In each experiment a Sole was placed in an aquarium without sand on the bottom, and left without food for two days. Then a Lugworm, Arenicola marina, was presented, and the time of swallowing by the Sole noted down. At given times afterwards the Sole was caught, killed, and the gut removed and preserved in the same way as for the animals sampled at sea, to make these results comparable with the field observations. The intestinal tract was examined two days afterwards for its contents as described above, the results of which are summarized in Table II. Although the data are inconclusive they show a tendency to confirm the results obtained from the animals caught at sea.

TABLE II

Speed of transport in the intestine of captive animals

\begin{tabular}{cccccc}
\hline $\begin{array}{c}\text { Time of digestion } \\
\text { in hours }\end{array}$ & Stomach & $L_{1 a}$ & $\frac{L_{1 b}}{\text { Presence of food in }}$ & $L_{2 a}$ & $L_{2 b}$ \\
\hline 6 & - & - & + & + & + \\
6 & + & + & + & + & + \\
12 & + & + & + & + & + \\
12 & + & + & + & + & + \\
14 & - & + & + & + & + \\
14 & + & - & + & + & + \\
18 & + & + & + & + & + \\
18 & - & - & + & + & + \\
24 & - & - & - & - & -
\end{tabular}

2. PERIODIGITY IN THE LOCOMOTION OF CAPTIVE SOLES

\section{Material and methods}

Observations were made in a $100 \times 50 \times 50 \mathrm{~cm}$ fibreglass aquarium, with a clear glass window on one side, the bottom covered by a layer of sand of about $5 \mathrm{~cm}$ deep. The water was aerated and filtered, and kept at $14-17^{\circ} \mathrm{C}$. The aquarium was placed under a horizontal, semitransparant window. The light intensity at the bottom of the aquarium during midday reached $100-500 \mathrm{erg} / \mathrm{cm}^{2} / \mathrm{sec}$. The niche in which the aquarium was standing could be curtained off from the main room by a roller blind, making it possible to deal with the recording apparatus etc. without visually disturbing the fish. In the aquarium three specimens of Solea vulgaris, about 2 years old, were kept together and now and then replaced, so that in all a total of 12 fish was used for the experiments. 
In order to obtain a more exact picture of the activity of the fishes during each 24-hour period a recording apparatus, represented in Plate I fig. I was used. In a framework of "Dexion" aluminium twenty contact elements were suspended, four from each of five horizontal bars about $60 \mathrm{~cm}$ above the surface of the water. Each contact element consisted of a small lead ball $4 \mathrm{~mm}$ in diameter, attached to the end of a length of nylon gut, in such a way as to hang just above the surface of the sand bottom, almost touching it. About $10 \mathrm{~cm}$ above the surface of the water each wire passed through a narrow opening in one of five aluminium bars parallel to those previously mentioned and connected with one pole of an electric circuit. Just where the wire passed through the opening, the polythene was replaced by a thin metal wire, connected via much thinner wires with the opposite pole of the circuit. 'Thus, when one of the lead balls was moved, contact of the metal wire with the aluminium bar closed the circuit. The electric current so produced was recorded on a kymograph, using a relay.

In this way, the number of spikes made by the relay recorder on the kymograph gave a measure of the number of times that the lead balls were touched by the fish in the tank. A time recorder gave spikes at regular time intervals, allowing the number of "activity-spikes" per time unit to be read directly from the recording.

Observations of the Soles in this arrangement gave no indications that they treated the lead balls as being in any way different from natural obstacles, e.g. large grains of sand: many times the animals were observed shifting the lead balls while slowly moving over the sand, or even touching the polythene wires when performing the "Omegajump" (see below). Recordings were occasionally invalidated and so discarded due to the permanent shift of a ball by the digging activities of the fish; but other than this, the number of spikes on the kymograph may be considered a good measure of the normal activity of the fish in the aquarium.

The experiments were done on days that no food was present in the aquarium, although, when the animals had been fed sufficiently, presentation of food at any time of the day did not alter the daily periodicity as revealed in the recording. Only when the Soles had been without food for some days was it possible to change this picture; then, even at midday, the fish would become active directly after food presentation, but would then become inactive again until the evening. 


\section{Results}

During December 1959 and January 1960 a total of 14 24-hour activity records was obtained. The results of these 14 recordings are given in fig. 5b. The data show that there is a strong tendency for activity to take place during the hours of the night with a peak at about $23.00 \mathrm{hrs}$. A second, lower maximum in the activity occurs at about $5.00 \mathrm{hrs}$. A steep increase and decrease can be noticed around sunset (about $16.00 \mathrm{hrs}$.) and sunrise (ca. $8.30 \mathrm{hrs}$.) respectively; around midday the activity goes down to zero.

In the same figure a graph is given, representing the catch of the Sole by trawl per hour (from STAM, 1952); the obvious correlation between the two measurements will be discussed below (section $\mathrm{V}$ ).

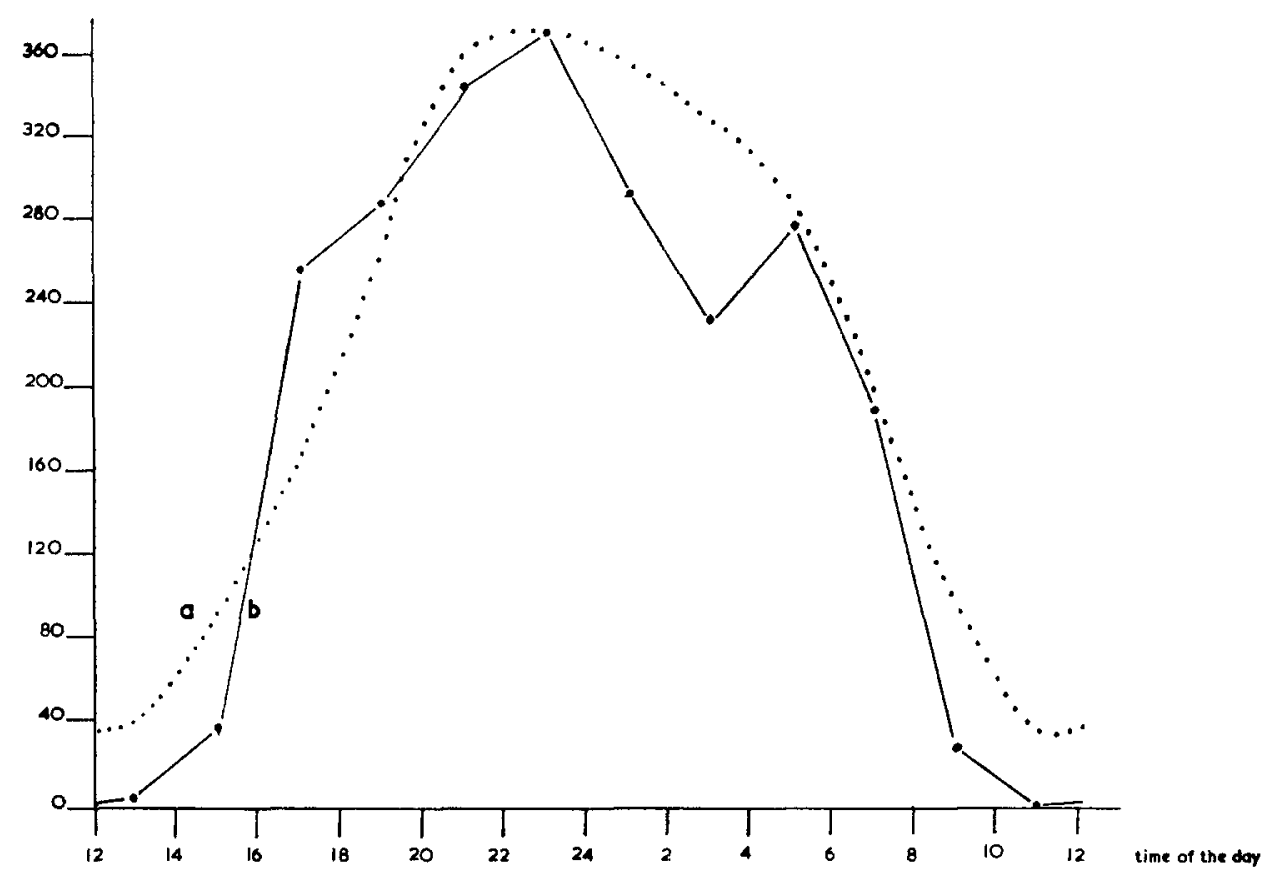

Fig.5. a. Percentage of the maximum catch per hour of Soles in kg. for January and February. Vertical $=2 \times$ the percentage of the maximum catch (from STAM, 1952).

$b$. Total number of activity recordings per two hours of the activity of Soles in the aquarium under natural light conditions. Fourteen experiments in December and January. Vertical = number of activity-spikes. 


\section{CONCLUSIONS}

By examining the food intake of Solea an attempt has been made to study the periodical activity of this fish in its natural habitat. From data on the percentage of Soles having food in the gut, at different times of the day, it is not possible to draw any conclusions with regard to a daily fluctuation in the food intake; obviously, the percentage of animals having food in the gut does not change very much during the day. Any possible trend in these figures will certainly have been obscured by the strikingly great variation in food quality between the samples, presumably due to feeding in different areas.

On considering the separate parts of the intestine, however, it becomes clear that there is indeed such a fluctuation during the day. The percentage of animals with food in the fore-part of the intestine has a maximum at about midnight and a minimum at the end of the afternoon; the percentage of animals with food in the hind-part of the intestine shows the reverse (fig. 3). Or, at midnight we find the bulk of the food in the fore-part of the intestine, at the end of the afternoon in the hindpart (fig. 2).

The data suggest that food intake takes place with a maximum intensity at midnight and a minimum during the day, and that the transport of food would take about 18 hours, from the stomach to the anus. It will be shown in a separate publication that we are justified in assuming that food intake takes place during the activity period. Therefore, it seems reasonable to conclude from our figures that in its natural environment Solea has a daily activity rhythm with a maximum at about midnight and a minimum during the day. Measurement of activity in the aquarium confirmed this, showing a clear diurnal periodicity in the locomotory activity.

A distinct feature in the aquarium activity curve is the occurrence of the second peak in the activity, at about $5.00 \mathrm{hrs}$. This, apparently, is neither found in the fishery curve nor in the feeding cycle (although this last measurement may be not sensitive enough to indicate a feature like this). It will be shown later (section IV) that this second maximum occurs at about the same time even when the first maximum is shifted. This suggests that the two peaks are controlled in a different way, but for the time being the question of whether this phenomenon is a natural one or an artefact of the experimental environment has to be left open. 


\section{BEHAVIOUR PATTERNS IMPORTANT IN THE DAILY AGTIVITY GYCLE OF THE SOLE}

\section{GENERAL DESCRIPTION}

In the previous sections it has been shown that the Common Sole is essentially a nocturnal animal, inactive during the day. In the aquarium Soles spend the whole day lying in the sand, entirely covered, with only the upper half of the mouth, one of the nasal organs, and the eyes free (Plate I, fig. 2). At the end of the day the animal becomes active rather suddenly. The sand is thrown off the back with a typical movement, which we will call the "Omega-jump", because of the similarity of the course of the movement with the Greek capital $\Omega$, and the animal begins to move over the bottom. This movement is slow and shambling, with many changes in direction, lying still, going backwards etc. Locomotion takes place by the action of the finrays of the dorsal and anal fins on the surface of the sand (Plate II,fig. 1). Only occasionally does the fish leave the bottom for real free swimming, and rarely it may even swim at the surface of the water.

At dawn the Sole stops moving, preferably in a depression in the sand, in the aquarium often returning to the same spot each day. In this place the fish makes a series of hard, beating movements on the sand, the "digging-in" movements, which cover the animal with sand. From then on, the fish stays absolutely still in the sand, apart from respiration movements.

Thus, in the daily activity cycle, there are always two important turning points: the Omega-jump, and digging-in. In the following sections we will consider some causal factors of those behaviour patterns, and the function they have within the daily rhythm.

\section{TERMINATION OF THE ACTIVITY PERIOD: THE "DIGGING-IN"}

\section{Description}

One series of digging-in movements consists of 3-8 hard beats with the head on the sand; each beat is the beginning of a travelling wave through the body, which decreases in amplitude as it proceeds. The head beats are remarkably vigorous and may even be heard outside the aquarium. By means of the beats the sand under the body is whirled up and partly falls on the body of the fish and on the long dorsal and anal fins. During this series of beats the fin rays of the dorsal and anal fins 


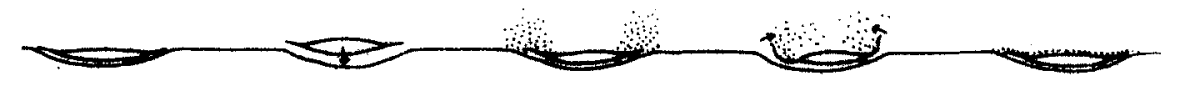

Fig.6. Schematic cross-section through a Sole digging-in on a sandy bottom. Explanation see text.

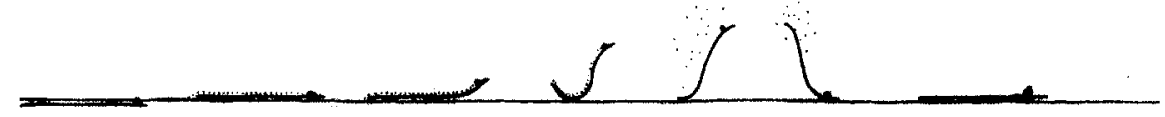

7. The Omega-jump. Explanation see text.

show vertical movements which are in several aspects different from locomotory movements (Plate II, fig.2); they cause the sand to be thrown from the fins over the whole back of the fish (fig.6). One series of digging-in movements lasts for about $\frac{1}{2}-1$ second.

\section{Causal factors; experiments on the influence of changes in light intensity'}

The digging-in may occur in a number of situations: as a fleeingreaction (after a push against the tank, pursuing with a stick, sudden flashing of light, etc.), sometimes directly after swallowing food, and also at dawn. In the first case the digging-in is clearly a reaction to changes in the environment, in the second it seems to be determined purely by internal factors. We will be mainly concerned with the third situation, which could be controlled by internal or external factors, or perhaps both. Here, we will consider the influence of external factors on the movement.

Normally, on a sandy bottom, we observe only one series of diggingin movements; then the animal is covered and lies still. If we keep the Sole in a tank without sand on the bottom, however, one series of digging-in movements may be followed by several others, once the digging-in is released. This may also happen when the fish is not entirely covered with sand after one series of digging-in movements on a sandy bottom. This observation suggests that being covered with a layer of sand inhibits the occurence of further digging-in movements. The digging-in of blinded Soles is exactly the same, which would imply that it is a non-visual (probably tactile) stimulus which causes this inhibition.

So, the digging-in is only performed by animals which are not covered with sand. The external factor which would be likely to play a role in 
the direct releasing of the digging-in at the end of the night is the change in light-intensity, and some experiments were designed to study possible relationships.

\section{Experimental set-up}

Since tank observations showed that the Soles are influenced by even very low light intensities visual observation of the experimental animal was impossible, and their reactions to changes in light-intensity were recorded in another way, mechanically, in the following set-up (fig. 8).

An animal was placed in a rectangular glass container, $30 \times 20 \times$ $20 \mathrm{~cm}$, with a thin polythene membrane as a bottom. This container was suspended in a larger aquarium in such a way that the water was equally high in both. Thus, movements of the polythene membrane could be recorded via a wire and a recorder pen on a kymograph. Above the container with the animal an electric bulb was fixed, the light intensity of which could be varied at any speed required by means of a liquid-resistance. To eliminate the concurrent effect of changes in the quality of the emission spectrum of the bulb, a liquid-filter with a saturated solution of copper--sulphate was attached between the bulb and the container with the animal, so that only the blue-green part of the spectrum was transmitted. The relative composition of the light thus transmitted at different intensities, when checked by a gauged selenium-cell with interference filters, showed the change in light-

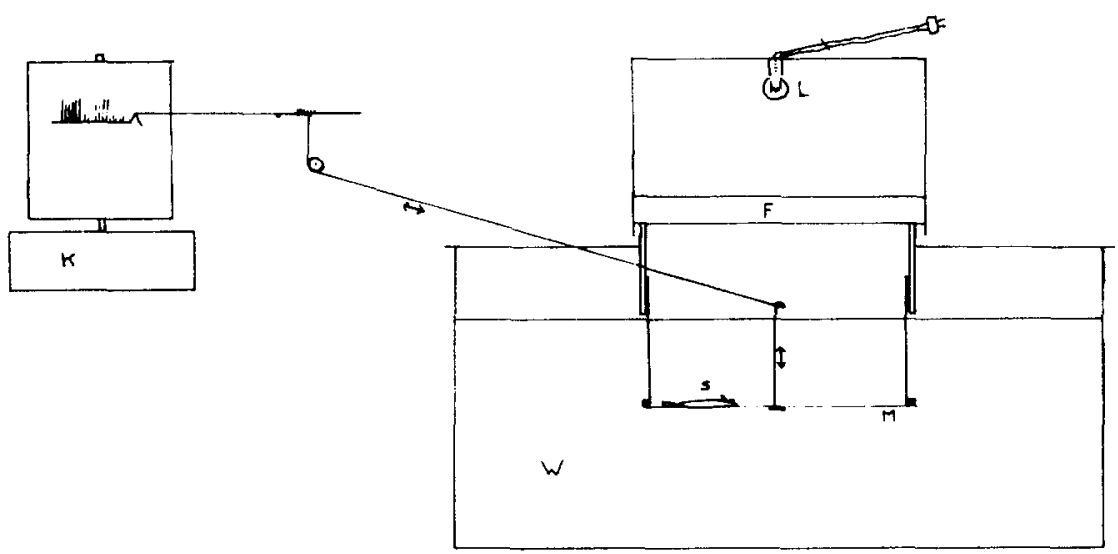

Fig. 8. Experimental set-up for the recording of digging-in movements. $F=$ filter with copper-sulphate $\mathrm{K}=$ kymograph $\mathrm{L}=$ lightbulb connected with a resistance; $\mathbf{M}=$ polythene membrane; $\mathbf{S}=$ Sole; $\mathrm{W}=$ water. 
quality with changing light-quantity to be very small indeed", and therefore negligible. A second advantage of the use of the coppersulphate filter lies in the fact that the composition of the light thus transmitted is rather similar to the composition of the light at some depth in the sea. The entire set-up of the large aquarium, bulb and filter was screened off from other light sources. By means of the seleniumcell the quantity of the light cast on the polythene membrane could be determined for different resistances.

Since it was not possible to make any direct light measurements in the natural habitat of the Sole for planning the experiments, a rough estimate of the kind of light changes which take place there was made indirectly. At $c a .52^{\circ} \mathrm{L} . \mathrm{N}$. the light intensity on a horizontal surface during midday may vary from $10^{3} \mathrm{erg} / \mathrm{cm}^{2} / \mathrm{sec}$. on a cloudy winterday to about $10^{6} \mathrm{erg} / \mathrm{cm}^{2} / \mathrm{sec}$. on a bright summerday. Intensity increases sharply from dawn until 2-3 hours after sunrise, and changes only relatively little during the further part of the day until 2-3 hours before sunset, when a steep decrease sets in (Clarke and Backus 1956). The increase and decrease in light intensity lasts somewhat longer in summer. On a horizontal surface under water the effect of this sharp increase and decrease is even more pronounced.

If we use the average extinction coefficient for coastal waters for $e . g$. yellow-green light from Clarke (1954) we find at a depth of $30 \mathrm{~m}$ in the North Sea (which is a depth at which a dense Sole population occurs) still about $0.1 \%$ of the surface light intensity. From this we may derive that on a cloudy winter day at midday this habitat of the Sole is illuminated with an intensity of about $1 \mathrm{erg} / \mathrm{cm}^{2} / \mathrm{sec}$; for a sunny summer day this figure would be $1000 \mathrm{erg} / \mathrm{cm}^{2} / \mathrm{sec}$.

This calculation is obviously very rough indeed, and ignores irregular factors like waves and troubled water, which may enter into the picture. But it may provide a sufficient basis for determining the order of magnitude of the light intensities and and changes in light intensity for the following experiments.

The kymograph recording consisted of a straight line, with long or very short spikes. Observations of the experimental animal and the recording at the same time showed that the long spikes were caused by series of digging-in movements, the short spikes by normal locomotion, the two categories clearly distinct. Once the starting times, the speed of light intensity change and the speed of the recorder kymograph were known, the light intensity could be calculated for each point of the recording.

As a rule, a fish was kept for at least one day, mostly two days, in the experimental set-up before any work was done with it. The few animals for whom the experimental situation proved to be "too artificial" (who remained restless, did not eat, and did not react to any of the offered light stimuli), were excluded from further experimentation.

1 The data are too bulky to be published in this paper. 


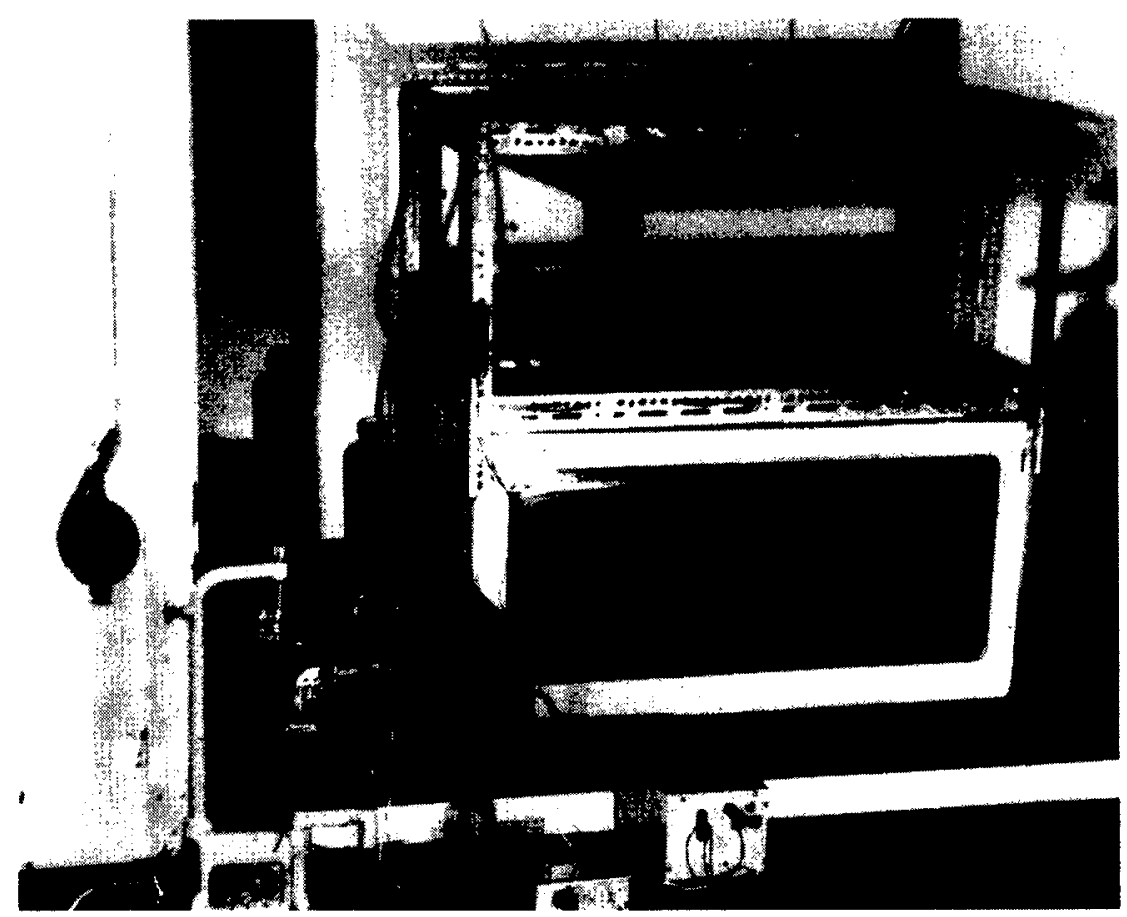

Fig. 1. Experimental set-up for recording of activity.

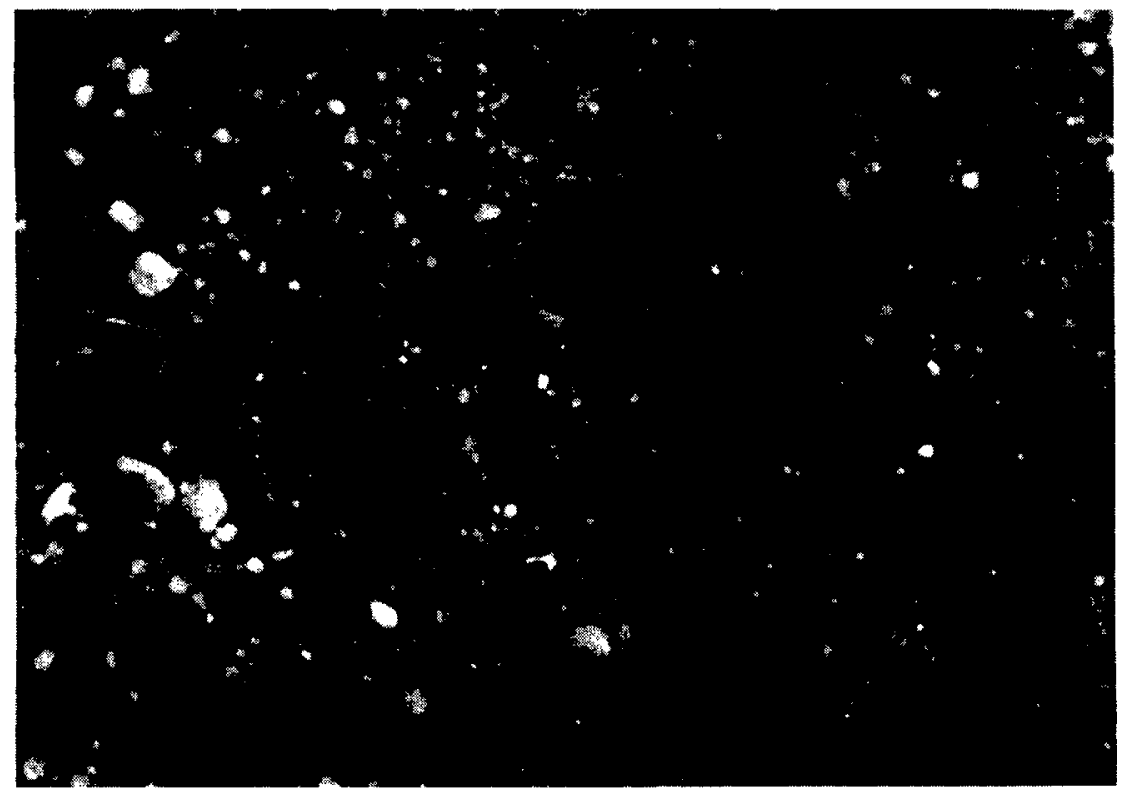

Fig. 2. Sole in the sand. Only eyes, mouth and a nostril are visible. 


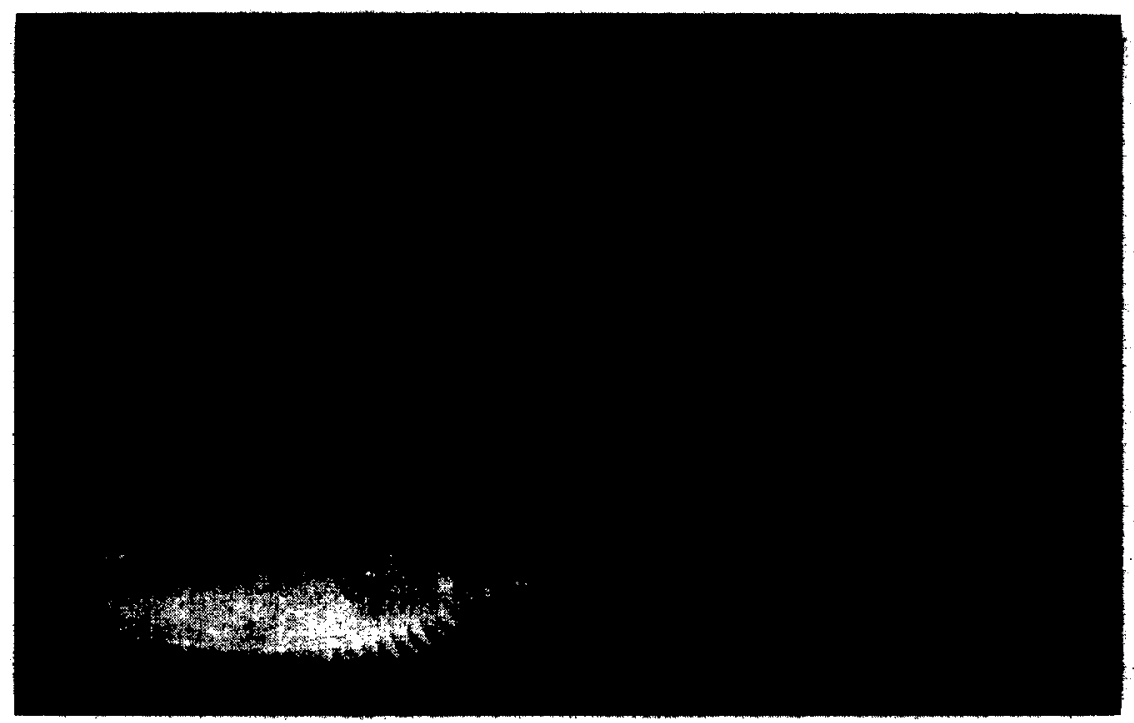

Fig. 1. lin mormm during locomotion. The picture is taken on a the fon without sand.

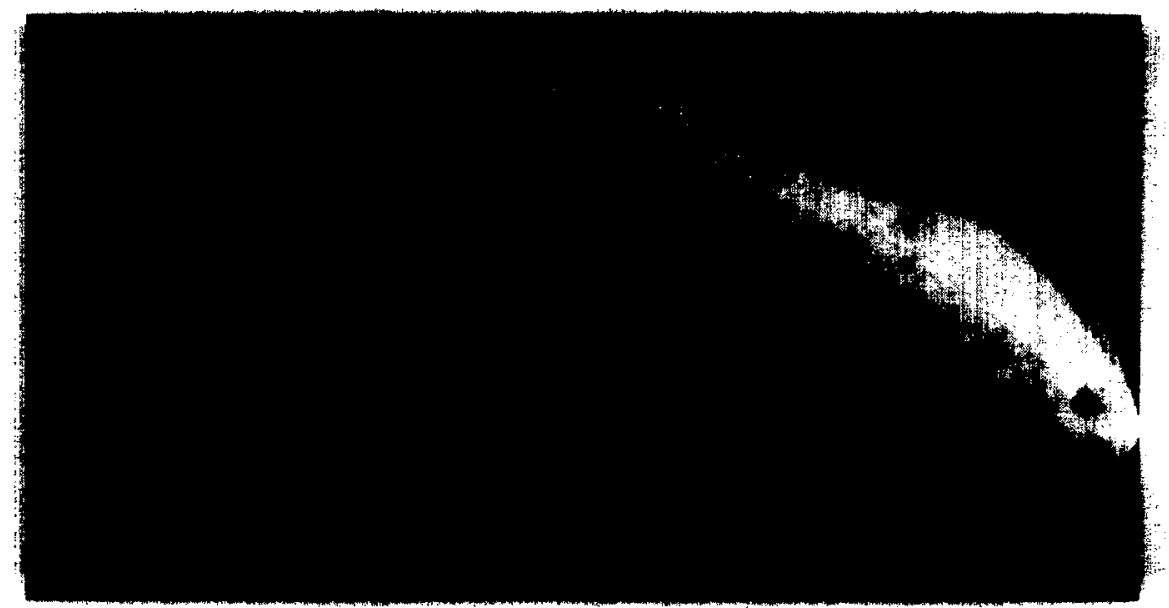

Fig. 2. Fin moveme:uts during digging-in. The picture is taken on a butten without sand. 


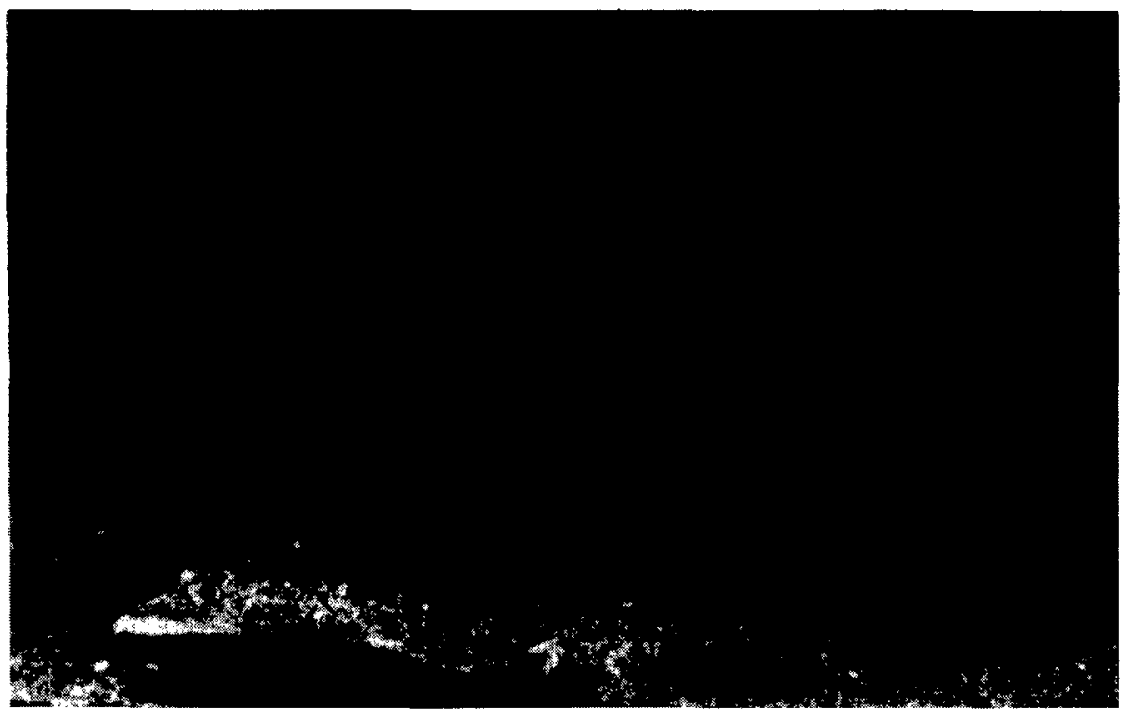

Fig. 1. Initial stage of the Omega-jump. Sole coming out of the sand, lifting its head.

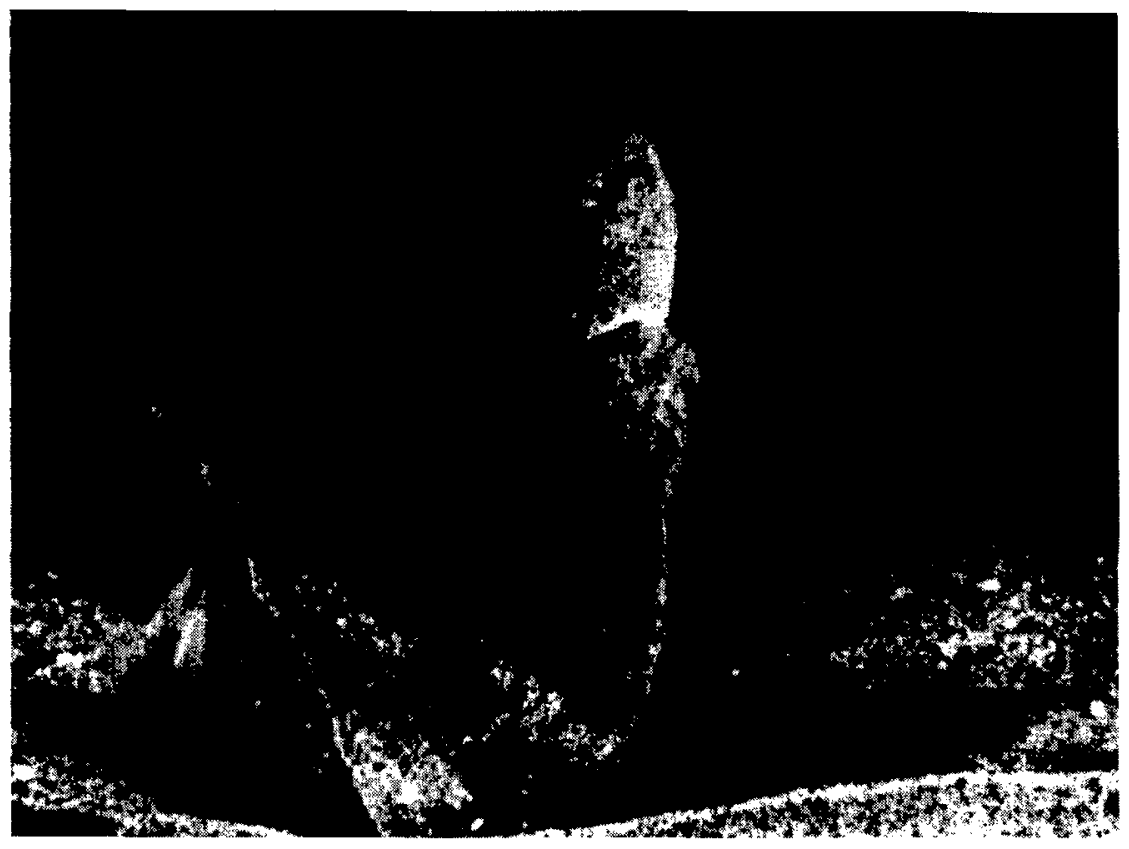

Fig.2. The Omega-jump. The tail is just about to give a stroke on the bottom. Sand still on the back. 


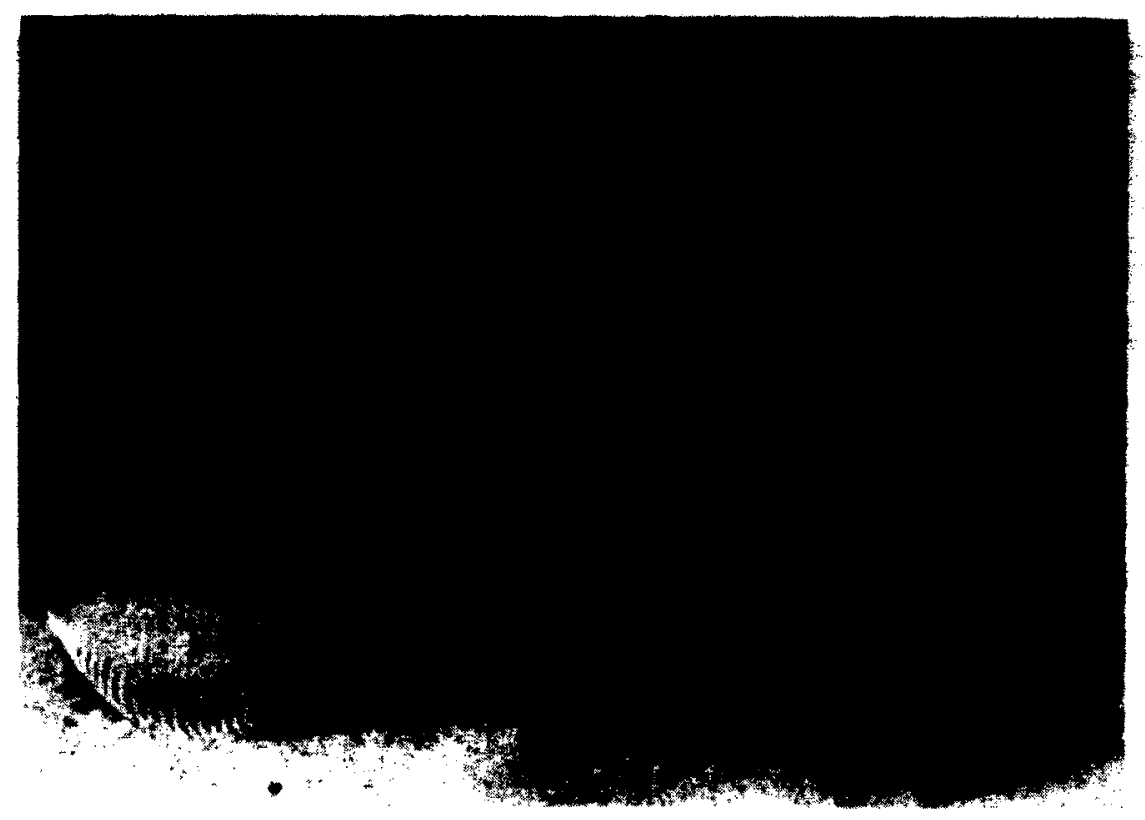

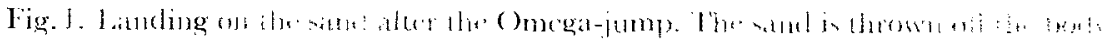

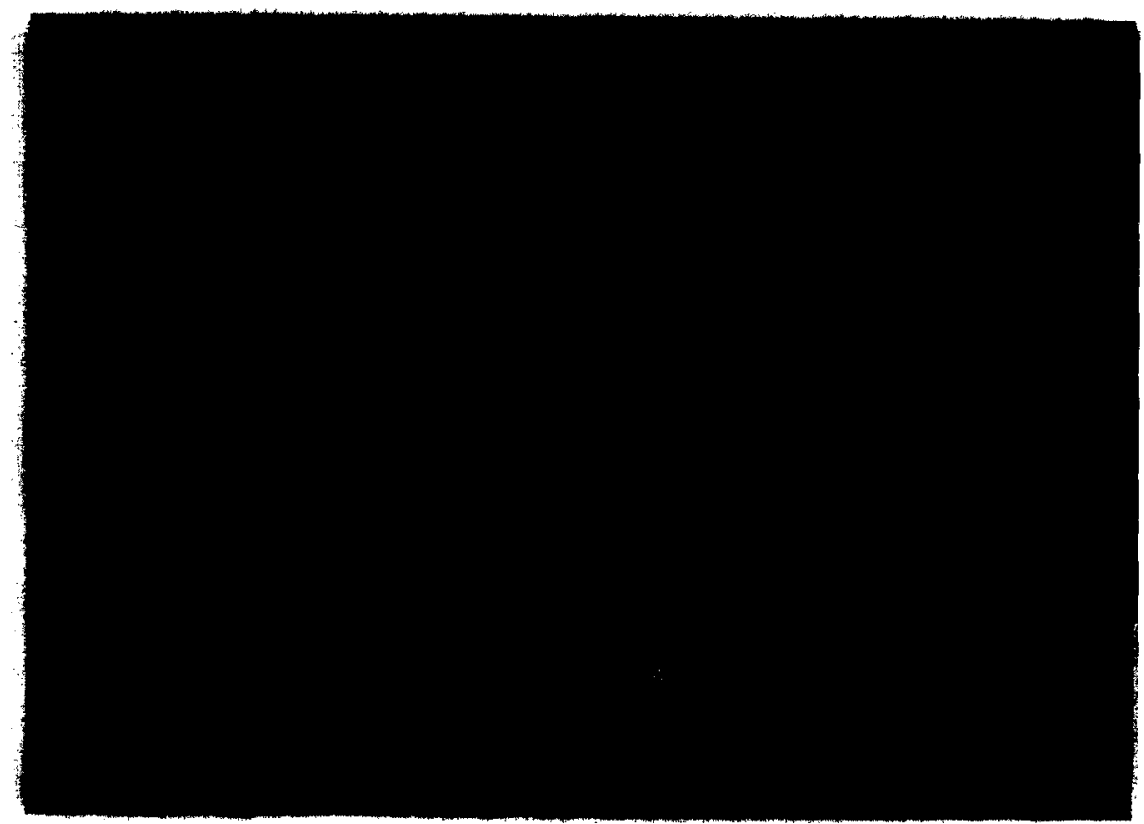

Fig. 2. Sole swimming on after the Omega-jump. The arch described by the hisk is still visible as a cloud of sand grains. 
The experiments

$a$. In the first place experiments were carried out to establish the influence of a sudden increase in light intensity. A fish was kept in complete darkness in the container for about one day, then registration of the membrane movements was started about one hour before the light was suddenly switched on. The light was kept on for a time up to three hours at an intensity of $100 \mathrm{erg} / \mathrm{cm}^{2} \mathrm{sec}$. (measured on the polythene membrane), then switched off. Some time later the recording was stopped.

From a fish in the dark no digging-in spikes were observed; but immediately after switching on the light one series of digging-in movements occurred, soon followed by others. In the first ten minutes an average of 7.6 series was observed, and this frequency decreased asymptotically to an average of 0.3 series per ten minutes after 200 minutes (Table III). When the light was switched off sometimes a few diggingin movements were still observed, but in general the animal kept still from then on.

$b$. In the second place the effect of a slow increase in light intensity was studied. Again, a fish was kept in complete darkness for about one day. Then the recording apparatus was started, and some time later the change in resistance. This caused an increase in light intensity on the polythene membrane of 0 to $350 \mathrm{erg} / \mathrm{cm}^{2} / \mathrm{sec}$. in 72 minutes. The light intensity at the instant when the Sole began performing the digging-in movements then could be calculated from the recording. The results are given in Table IV. It appeared that a median value of $0.35 \mathrm{erg} / \mathrm{cm}^{2} / \mathrm{sec}$. is sufficient to release the digging-in, in these ex-

T A B L E II I

Number of digging-in reactions per ten minutes after a sudden increase in light intensity

$\begin{gathered}\text { Number of } \\ \text { experiments }\end{gathered}$
$\cdots$
10
10
10
9
9
9
9
9
9
9
-

\begin{tabular}{cc|ccc}
$\begin{array}{c}\text { Time in } \\
\text { mimutes after } \\
\text { light-increase }\end{array}$ & $\begin{array}{c}\text { Average } \\
\text { number of } \\
\text { reactions }\end{array}$ & $\begin{array}{c}\text { Number of } \\
\text { experiments }\end{array}$ & $\begin{array}{c}\text { Time in } \\
\text { minutes after } \\
\text { light-increase }\end{array}$ & $\begin{array}{c}\text { Average } \\
\text { number of } \\
\text { reactions }\end{array}$ \\
\hline 10 & 7.6 & 9 & 110 & 1.7 \\
20 & 5.8 & 9 & 120 & 0.9 \\
30 & 3.8 & 8 & 130 & 0.9 \\
40 & 3.2 & 8 & 140 & 1.0 \\
50 & 2.8 & 7 & 150 & 0.6 \\
60 & 1.6 & 7 & 160 & 0.8 \\
70 & 2.2 & 7 & 170 & 0.6 \\
80 & 2.2 & 7 & 180 & 0.6 \\
90 & 1.3 & 6 & 190 & 0.5 \\
100 & 1.1 & 6 & 200 & 0.3 \\
& & & &
\end{tabular}


Light intensities at which the first digging-in reactions were recorded during an increase in light intensity in 70 minutes from 0 to $350 \mathrm{erg} / \mathrm{cm}^{2} / \mathrm{ser}$.

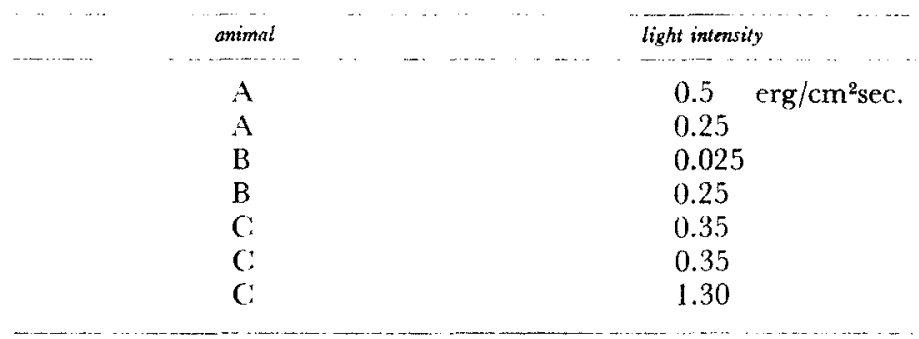

Median value $0.35 \mathrm{erg} / \mathrm{cm}^{2} / \mathrm{sec}$.

perimental conditions. Here again, the first digging-in series is followed by more and the movements stop when the light is switched off or when the light intensity slowly decreases again.

3. BEGINNING OF THE ACTIVITY PERIOD; THE "OMEGA-JUMP"

\section{Description}

After having spent the day motionless in the sand the Sole may start its active period by moving a short distance over the sand surface (usually from 0 to $20 \mathrm{~cm}$, but sometimes even up to $1 \mathrm{~m}$ ), with the layer of sand on its back. The head is lifted then, relatively slowly, the rest of the body following till only the hind half of the fish rests on the sand. Then, in a rather sudden movement the tail lifts almost perpendicular to the sand surface, and gives a stroke on the bottom which may be heard even outside the tank. This causes the fish to describe a short arch in the water, after which it lands again on the sand (fig. 7, Plate III figs. 1 and 2; Plate IV figs. 1 and 2).

Before the actual Omega-jump is performed the head may be lifted several times and put down again (probably intention movements to jump). During the jump the sand is thrown off the back (figs. 15 and 16). From the moment of head-lifting to the tail-stroke, -2 seconds may pass; after the tail-stroke the fish usually lands on the sand within a fraction of a second, about $20-30 \mathrm{~cm}$ from its starting-point. All these figures are for Soles of $17-24 \mathrm{~cm}$ long.

It should be mentioned that the Omega-jump does not always occur at the end of a non-activity period. Although no actual counts have 
been made, in probably less than $5 \%$ of observed cases the Sole began its activity without the jump; the sand then disappears from the back during the course of the activity.

\section{Causal factors; experiments on the influence of changes in light intensity}

The Omega-jump occurs only at the end of a non-active period, at the beginning of locomotory activity. This may be at the beginning of the night, or when the fish is coming out of the sand after a disturbance. In some hundreds of observations it has been observed only in animals having sand on the back and never in animals on a sandy bottom which had not been dug in, or animals becoming active on a non-sandy bottom.

Thus, carrying sand on the back seems to be part of the stimulus situation for releasing the Omega-jump. "Becoming active" seems also to be necessary, although the occurrence of the Omega-jump does not seem to be absolutely linked with the beginning of the activity, since in a small number of cases the animal starts locomotion without the Omega-jump. Therefore, the beginning of activity has to be treated separately, and in this section we will deal with the question of whether this may occur as a direct response to a change in light intensity, this being the most obvious change in the environment at the time when the daily non-active period ends.

Experiments were done in the set-up in which the locomotion fluctuations were studied (Plate I, fig. 1). On top of the aluminium frame work on the aquarium a bulb plus liquid-filter of copper-sulphate was placed, and the lamp was connected with the resistance in the same way as for the digging-in experiments. The aquarium was placed under a horizontal window in a niche of a cellar, and therefore exposed to the daily fluctuations of natural light. In December and January, when the tests were done, it was entirely dark at $18.00 \mathrm{hrs}$. However, at $16.00 \mathrm{hrs}$. the light above the filter was switched on, causing at that moment a relatively small increase in light intensity on the bottom of the tank. The light was left on until a given time during the evening, then decreased slowly, bringing the light intensity on the bottom of the tank from $80 \mathrm{erg} / \mathrm{cm}^{2} / \mathrm{sec}$. down to $0.02 \mathrm{erg} / \mathrm{cm}^{2} / \mathrm{sec}$., when the light switched off entirely. It was then possible to calculate, from the activity record and the known speed of light decrease, the light intensity at the moment the first activity was recorded.

Each test was done with three fish in the aquarium; different individuals being used in the first four and in the last five experiments. In Table $\mathrm{V}$ the results of 9 experiments are presented. 
TABLE V

Beginning of activity during a decrease in light intensity from 80 to $0.02 \mathrm{crg} / \mathrm{cm}^{2} / \mathrm{sec}$. When the intensity 0.02 was reached, light was turned out entirely. Threc animak in each experiment.

Time of beginning of decrease

19.00

18.30

18.30

18.30

18.30

18.30

22.00

22.00

22.00

Duration of the total decrease
$72 \mathrm{~min}$.
120
120
120
120
120
120
120
120

Median value $0.08 \mathrm{erg} / \mathrm{cm}^{2} / \mathrm{sec}$
Light intensity at first recorted actiuty

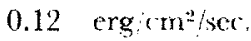

0.056

0.15

0.19

0.035

$0.00^{3}$

0.35

0.08

$0.00^{2}$

120 minutes after the light was turned out.

It appeared that in these experimental conditions the Soles did not begin their activity until the light intensity decreased to a median value of $0.08 \mathrm{erg} / \mathrm{cm}^{2} / \mathrm{sec}$. There are no statistically significant differences between the outcomes of the experiments at $18.30 \mathrm{hrs}$. and $19.00 \mathrm{hrs}$, and those at $22.00 \mathrm{hrs}$.

\section{CONCLUSIONS}

Digging-in is a behaviour pattern which, as mentioned above, occurs in several different circumstances. For the moment, we are interested in its role in the daily activity cycle, and since light intensity is one of the most strikingly changing features within the daily period, a possible relation between the changes in light intensity and the occurrence of digging-in has been postulated. It appears from the experiments that digging-in can indeed occur as a reaction to change in light intensity alone, be it sudden or slow. If we increase the light intensity at a speed not too different from the natural speed of change, a light intensity of about $0.35 \mathrm{erg} / \mathrm{cm}^{2} / \mathrm{sec}$. appears to be sufficient for releasing the response. If sand is absent and the stimulus for digging-in remains constant one series of movements is followed by many others, the frequency of occurrence decreasing asymptotically. The fact that the behaviour pattern is repeated is a confirmation of observations in the 
aquarium that, if the fish is not entirely covered by sand after one digging-in series, it will perform a series again. Once the animal is covered, it remains still. Since we may assume that covering of the body with sand is the main function of the digging-in, we find an interesting example here of the effect of a behaviour pattern inhibiting its further occurrence.

The results of the experiments on the beginning of the activity suggest that changes in light intensity play at least a large role in determining the beginning of the activity in the normal daily rhythm. The light intensity must decrease a great deal before any activity takes place, with a value of $0.08 \mathrm{erg} / \mathrm{cm}^{2} / \mathrm{sec}$. being the median intensity for the beginning of the activity in these experimental circumstances.

\section{ACTIVITY UNDER ARTIFICIAL LIGHT CONDITIONS}

To check on the importance of the daily light rhythm on the activity of the Sole some experiments were carried out in which suddenly the light periodicity was changed after the animal had been for some time under natural light. In this way, it should be possible to determine whether light is the only factor which influences the daily rhythm, or whether other factors also play a role. Thus, the activity was determined in continuous darkness, in continuous light and under conditions of a light cycle different from the natural one. Experiments were carried out in the same set-up as described in the previous section, with three animals at a time.

\section{ACTIVITY IN CONTINUOUS DARKNESS}

The window of the niche in which the aquarium was placed was entirely screened off at about $12.00 \mathrm{hrs}$; from then on the niche was kept dark for 48 hours. To avoid the possibility of environmental disturbances influencing the activity, experiments were done only when no other persons were present in the laboratory.

The total number of recordings per two hours for different times of the day from three experiments is given in fig.9. Each experiment was done with three different animals.

From the graph it can be seen that, although no changes in light intensity are present, a clear activity rhythm still remains. The experiments did not last long enough to show how persistent this rhythm would be, but even so some marked differences from the normal rhythm 
Total number of recordings

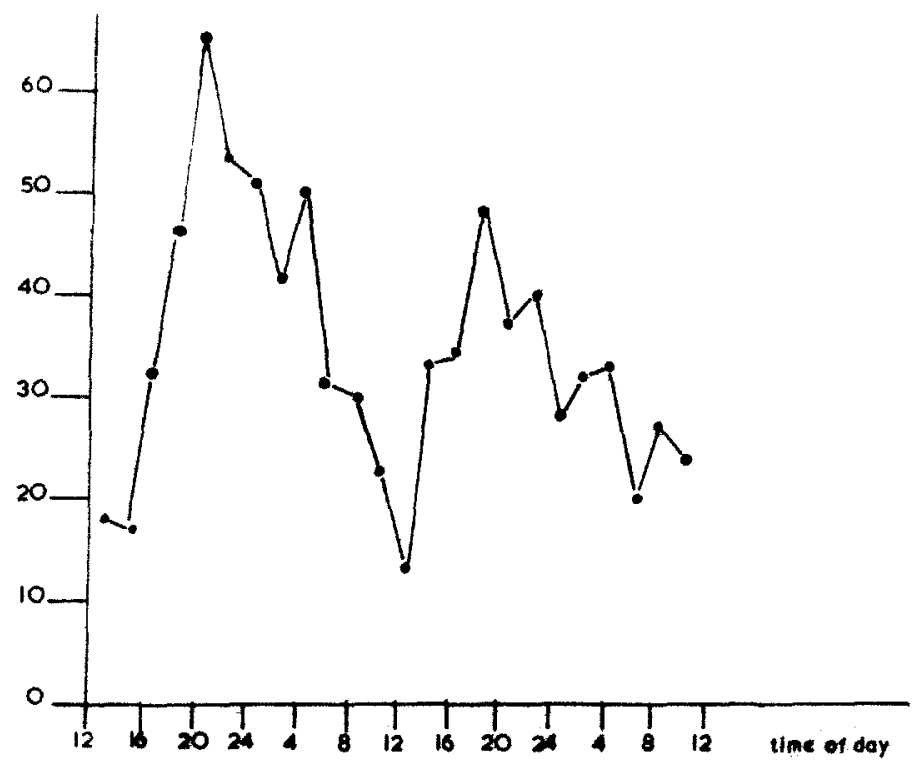

Fig. 9. Activity recordings during constant darkness: Three experiments of 48 hours. Vertical $=$ total number of recordings per two hours.

\section{Total no. of} recordings

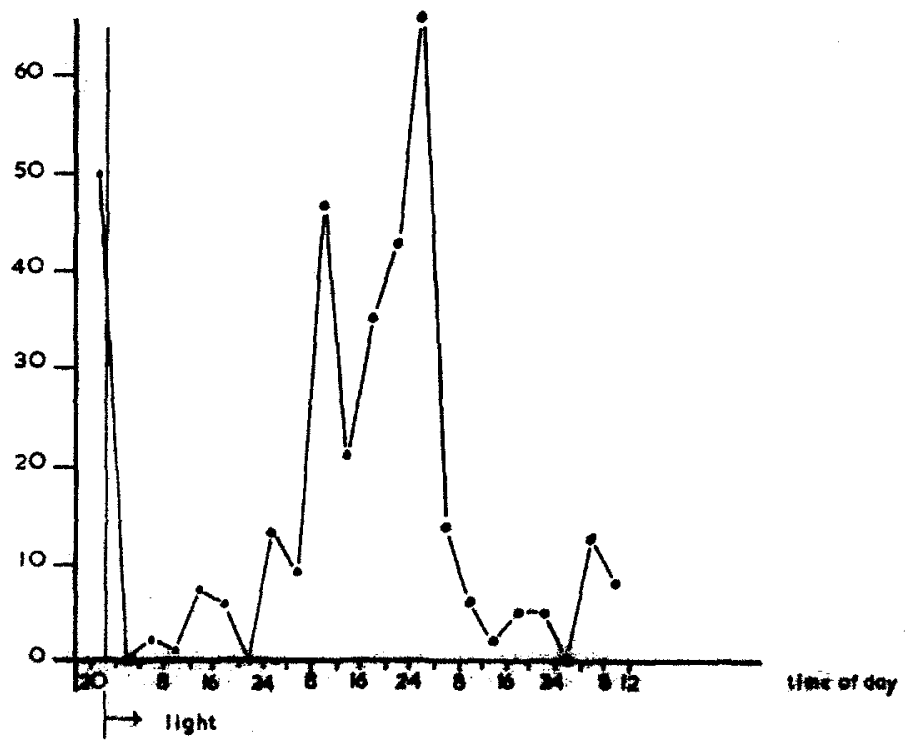

Fig. 10. Activity recording during constant illumination, from one experiment of 88 hours. Vertical = total number of recordings per four hours. 
should be noted. The maxima in the activity in this experiment are found earlier than under natural conditions, the first peak being recorded at about 21.00 hrs., i.e. two hours earlier, and the following day's peak at about $19.00 \mathrm{hrs}$, again two hours earlier. This suggests that, instead of a 24-hour rhythm, a 22-hour cycle might possibly be operating. A second interesting point is the fact that in continuous darkness during the "non-active period" the activity level is not so low as under the normal rhythm; in fact, it never reaches the zero-level. During a similar experiment not included here observations made during this period of low activity revealed that all three animals present were lying on the sand and not dug-in as in the natural situation would be the case.

Finally, it may be noted that at about $5.00 \mathrm{hrs}$. there is a small second maximum in both halves of the graph. This maximum also occurred in the natural rhythm but was more pronounced; it is of interest that this peak is not shifted here as is the first maximum.

\section{ACTIVITY IN CONTINUOUS LIGHT}

Again the aquarium niche was screened off entirely. Behind the fibreglass back wall of the aquarium an ordinary bulb was placed, so that the bottom was illuminated diffusely via the walls of the niche, with an intensity of about $100 \mathrm{erg} / \mathrm{cm}^{2} / \mathrm{sec}$. The light was switched on at 22.00 $\mathrm{hr}$. and left on for $3 \frac{1}{2}$ days. Three animals were used. The number of recording spikes per four hours for the course of the experiment is given in fig. 10.

After the light was switched on, the activity immediately dropped to zero level, remained very low for about 24 hours, then went up again, etc. Periodicity in the activity seemed to have disappeared entirely.

\section{ACTIVTTY UNDER A TWEIVE-HOUR LIGHT CYCLE}

The niche was darkened entirely and the lamp above the filter operated via a switch-clock, which automatically switched the light on and off in such a way that the aquarium was illuminated from $6.00 \mathrm{hrs}$. to $12.00 \mathrm{hrs}$. and from $18.00 \mathrm{hrs}$. to $24.00 \mathrm{hrs}$. with a steady light intensity of about $350 \mathrm{erg} / \mathrm{cm}^{2} / \mathrm{sec}$. Only one 8-day experiment was carried out, with three animals; the results of those eight days are combined and 


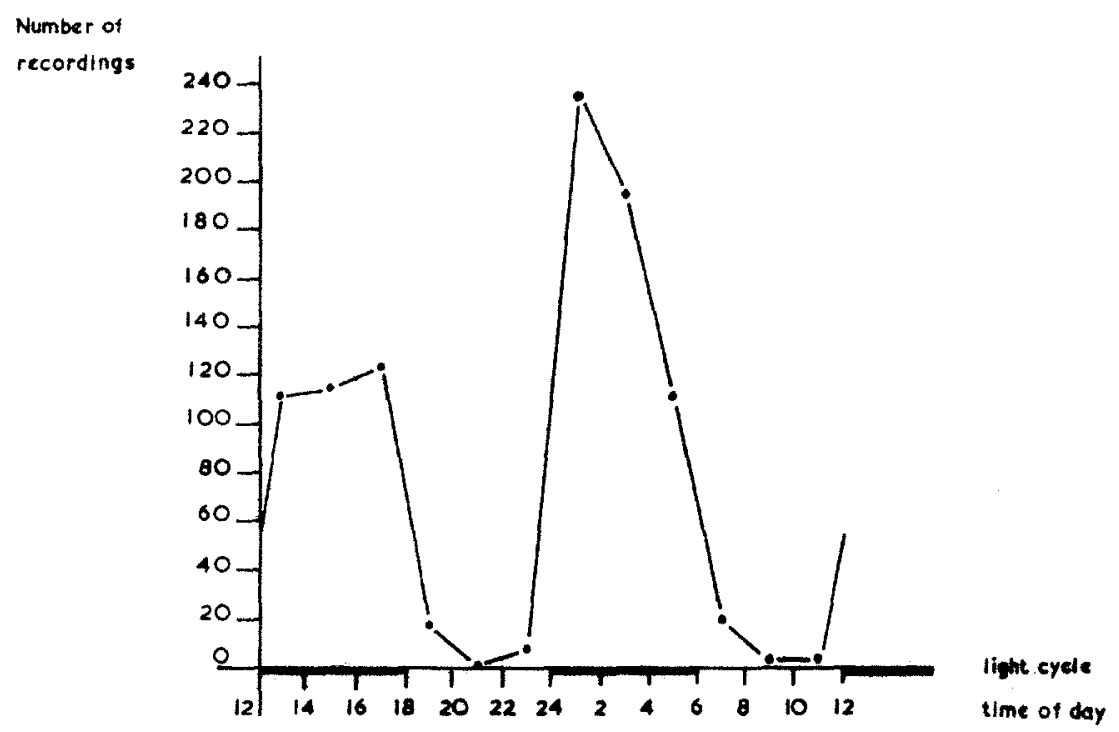

Fig. 11. Activity recordings in a light cycle of six hours dark, six hours light, from one experiment of 8 days. Vertical $=$ total number of recordings per two hours.

presented in fig. 11 , which gives the number of activity-spikes per two hours for the different times of the day.

From this graph we see that a clear activity rhythm appears to follow the light rhythm; but, in addition, the "natural rhythm" is still represented. Activity during the "day dark-period" is significantly lower than activity during the "night dark-period", suggesting that light rhythm plays an important role in the determination of the activity rhythm, but that another system is probably also operating.

\section{CONCLUSIONS}

From the above mentioned experiments it is clear that light cannot be the only factor which determines the activity of the Sole. A clear rhythm, possibly having a 22 -hour cycle, is present even in continuous darkness. This is confirmed by the results of the 12-hour light cycle experiment, which suggests a second rhythm to underly the light rhythm.

The different results obtained from the experiment in continuous darkness and the experiment in continuous light sugsest that two different mechanisms are operating here. This will be further diseussed below. 


\section{DISCUSSION; RELEVANGE TO THE QUESTION OF PERIODICITY IN TRAWL CATCHES}

For reasons explained above evidence for the existence of a diurnal rhythm in activity in the Sole has been gathered in two ways, in the natural habitat and in the aquarium. In the natural habitat the food intake was studied from the presence of food in the intestinal tract. From the clear rhythm that became apparent in food intake we conclude the existence of a daily fluctuation of the number of fish feeding, and thus, on the basis of the observation that Soles only feed when active, it is likely that there is a rhythm in the number of active fish.

In the aquarium the locomotory activity of the fish at different times was measured. Here, again, a clear diurnal rhythm appeared, similar to the one in the natural habitat. This made us confident in extrapolating observations relevant to the diurnal cycle from the aquarium to the natural situation.

The Sole appears to spend the day hours in, and the night hours on the sand. When the Sole is not active, it is covered by a layer of sand, with only the eyes, one nostril and the mouth free. At dusk the sand is disposed of with the Omega-jump and the fish starts feeding; at dawn it digs itself in again. It seems that both feeding and protection against predators make up a whole functional system within this daily rhythm. It will be shown in a later paper that food finding methods (chiefly olfactory and tactile) and daily rhythm are very well adapted to each other. During the day the animal is protected against predation by the layer of sand, but during the night, when the Sole is actively foraging, the layer of sand would hamper the animal in its movements, cover sense organs, and also be of no use as regards protection against visual predation, so that an elaborate behaviour pattern has been developed to dispose of it. The covering of sand could be of great survival value during the day, since quite a few larger sea fish are known to hunt by sight (also, it will probably protect the Sole against its main predator nowadays, man). The mechanism of digging-in (i.e., reaction to the light intensity, and inhibition by the layer of sand itself) seems to be well adapted to the needs.

The Omega-jump and digging-in are both behaviour patterns transitional between the two phases of the diurnal rhythm. It will be of great value to the animal to have these two phases adjusted to the light cycle. This adjustment appears to work through the releasing mechanisms of Omega-jump and digging-in, as has been shown in section III. That the synchronisation is very good became clear from the experiment with the twelve hours light cycle. Part of the mechanism 
may be explained by comparing the results of the continuous darkness and the continuous light experiments. In continuous darkness the stimulus for digging-in (i.e. a light intensity increase) is never given, so that the animal never becomes entirely inactive (although some cyclical phenomenon still operates). In continuous light the stimulus for bccoming active (i.e. a light intensity decrease) is never given, so that the animal remains inactive. After some time another stimulus arises (e.g. "hunger") and activity becomes controlled by an entirely different mechanism.

Protection against visual and other predation by the layer of sand will only be effective if the fish keeps still. This requirement is met to a great extent. When undisturbed only the infrequent and small respiration movements reveal the animal's presence. These movements stop at the slightest disturbance. A few experiments showed that it is very difficult to make a buried Sole leave the sand. During the day time, when the Soles were covered by sand, a horizontal bar $60 \mathrm{~cm}$ long with perpendicular projections of about $2 \mathrm{~cm}$ long, was towed over the bottom of a large tank $(2 \times 1 \times 1 \mathrm{~m})$, in which 15 Soles were present. The perpendicular projections ploughed through the upper layer of the sand, often actually touching the buried fish. Only very occasionally did a Sole swim away when touched in this way; usually the animals remained motionless. With an ordinary stick or with the hand it is also difficult to make a buried Sole swim; the animal may even be injured without attempting to escape by fleeing. Finally, the tendency to dig-in in a small depression in the sand is probably also adaptive as an antipredator device.

PERIODICITY IN THE CATGH BY TRAWL

It seems that all these aspects of the digging-in can largely account for the differences between the day and night catches of Sole. A fish has to swim in order to be caught by a trawl, and from the above it will be clear that, once a Sole is buried, it will be very difficult for the groundropes of the trawl (which stir up only a very thin layer of sand) to get the Sole out of the sand, swimming. Thus, the huge difference in catch per hour between day and night can be largely explained by this difference in accessability.

There are, however, some indications that there is something more to it. In fig. 5a, a curve is given (STAM, 1952), representing the catch per hour of Soles during 24 hours in January and February. The differences in catch between the different night hours are impossible to explain on the above basis, which would predict more uniform catches 
throughout the night. The parallel between the catch per hour curve and the activity graph (fig. $5 b$ ) is really striking, suggesting a connection between the two phenomena.

A possible mechanism which might explain these smaller differences between the catches is suggested (though admittedly very tentatively) by some observations in the aquarium. The Sole, when active, may react to a disturbance by remaining still where it is, by digging-in, or by swimming away. It is suggested that this initial response may determine the chance of being caught. If the fish digs itself in, it is less likely to be caught than otherwise. The impression was often gained that the Soles respond differently to a stimulus at different times of the night: it seemed that around midnight the animals were less likely to dig-in in response to a particular "danger stimulus" (knocking at the edge of the aquarium) than at other times, e.g. at the beginning of the night. This would mean that with increasing activity the Sole is more likely to respond with swimming rather than with digging-in. Critical counts of the response, however, still remain to be done.

Summarizing, it is concluded that differences in accessability of the animal cause the diurnal difference in catch. It is possible that a change in the behavioural response to the net accounts for further differences in the catch per hour during the night.

\section{SUMMARY}

1. The diurnal rhythm in the trawl catch of Solea vulgaris Quensel gave rise to this investigation into the diurnal activity rhythm of the fish.

2. Periodicity in the food intake of the Sole in its natural habitat was studied by analyses of the contents of the intestines. Food intake appears to have a maximum during the night and a minimum during the day. It is argued that this reflects a diurnal periodicity in locomotory activity.

3. In the aquarium, periodicity in the activity of the Sole was measured directly. Soles touched small lead balls suspended in the tank; the number of contacts was recorded automatically. Activity appears to be zero during the day, maximal during the night, thus confirming observations in the natural habitat.

4. The changes in behaviour during this diurnal cycle are described. An active and inactive phase are distinguished; the characteristic behaviour patterns between the phases (the Omega-jump and digging-in) were studied.

5. The diurnal activity cycle of the Sole is adjusted to the light cycle via the releasing mechanisms of the behaviour patterns studied. Some 
experiments were carried out in which the activity was recorded in. continuous darkness, continuous light and in a twelve hours light cycle.

6. The possible functions of the behaviour described are discussed.

7. The mechanism behind the daily periodicity in the sole catch by trawl is discussed. It is argued that the main difference between day and night in the catch per hour is brought about by a periodicity in accessability of the fish; a hypothesis is put forward to explain the differences in the catch per hour during the night.

\section{ACKNOWLEDGEMENTS}

The present study has been carried out in the Laboratory for Comparative Physiology in Utrecht and the Institute for Fisheries Research in IJmuiden, Netherlands; I wish to express my gratitude to Prof. Dr. S. Dijkgraaf and Prof. Dr. P. Korringa for their hospitality, help and criticism during the course of the work. I had much valuable discussion, for which I am very grateful, with the staff of both laboratories, especially with Dr. F. J. Verheyen and Messrs. L. J. Boerema and M. Roessingh. Mrs. J. H. HaAvie and Mr. I. J. Patterson were of a very great help with the preparation of the manuscript, and I want to thank them for their many criticisms.

\section{LITERATURE}

Bünning, E., 1958: Die Physiologische Uhr. Berlin-Göttingen-Heidelberg.

Clarke, G. L., 1954 : Elements of Ecology. New York-London.

Clarke, G. L. and Backus, R. H., 1956. Measurements of light penetration in relation to vertical migration and records of luminescence of deep-sea animals. Deep-Sea Research 4, 1-14.

CreutzberG, P. H., 1941. Waarnemingen over het voedselzoeken van schol, bot en schar. Unpublished report to the Zoological Station, Den Helder, Neth.

Harker, J, 1958: Diurnal rhythms in the animal kingdom. Biol. Rev. 33, 1-52.

HOAR, W. S., 1942: Diurnal variations in feeding activity of young salmon and trout. J. Fish. Res. Bd. Canada 6 (1), 90-101.

HOAR, W. S., 1958: The evolution of migratory behaviour among juvenile Salmon of the genus Oncorhynchus. J. Fish. Res. Bd. Canada 15, 391-428.

Jones, N. S., 1952: The bottom fauna and the food of flatfish off the Cumberland coast. J. Anim. Ecology 21, 182-205.

Kawamoto, N., 1955: Diurnal rhythms in phototaxis of fish. Rep. Fac. Fisheries, Prefectural Univ. of Mie, 2, 1, 7-17.

Spencer, D., 1939: Diurnal activity-rhythms in freshwater fishes. Ohio J. of Science, 39, 119-127.

STAM, A. B., 1952 : Enige onderzoekingen over de tong-populatie voor de Nederlandse kust. Unpublished report to the Institute for Fisheries Research, IJmuiden, Neth. 